\title{
UM EXPERIENCIAR DO PARTO: CONCEPÇÃO DE MULHERES SOBRE O PARTO DOMICILIAR
}

\author{
A CHILDBIRTH EXPERIENCE: WHAT DO WOMEN THINK OF GIVING BIRTH AT HOME
}

Cristiano Braga de Jesus Silva ${ }^{1}$

Camila Torres da $\mathrm{Paz}^{2}$

Andrea Jaqueira da Silva Borges ${ }^{3}$

Beatriz Guimarães Gentil Fraga ${ }^{4}$

Juliette da Silva Borges Simões ${ }^{5}$

O processo de parir é um momento marcado por sentimentos e emoções na vida da mulher, sendo o parto domiciliar definido como uma modalidade de parto natural e humanizado realizado na própria residência. Assim, este estudo teve como objetivo geral conhecer a concepção de mulheres sobre a experiência do parto domiciliar, incluindo as etapas do pré-parto, parto e pós-parto e, como objetivos específicos, traçar o perfil sociodemográfico das mulheres que pariram em domicílio; descrever a assistência durante as etapas do parto; e identificar fatores e participantes que influenciaram no processo. Trata-se de uma pesquisa qualitativa com abordagem descritiva, realizada em domicílios de um município do Recôncavo da Bahia. Participaram deste estudo dez mulheres que vivenciaram o parto domiciliar. Utilizou-se um roteiro semiestruturado e os dados foram analisados através da técnica de análise de conteúdo. Assim, constatou-se que as mulheres preferiram o parto domiciliar ao hospitalar. Dentre os fatores que determinaram essa preferência, destaca-se a participação dos familiares, a atuação da equipe, a adoção de métodos não farmacológicos e a alimentação durante o trabalho de parto. Dentre as complicações relataram: hemorragia pós-parto, laceração de períneo e complicações do recém-nascido. Sugere-se a elaboração de um projeto de lei com o intuito de regulamentar e valorizar a prática do parto domiciliar no Brasil, com destinação de recursos financeiros para a capacitação de pessoal e aquisição de recursos materiais para garantir a eficácia da assistência.

Palavras-chave: Enfermagem Obstétrica. Parto Domiciliar. Assistência de Enfermagem.

The process of giving birth is a moment marked by feelings and emotions in the life of women, and home birth is defined as a modality of natural childbirth performed in the home itself. Thus, this study aims to know the conception of women about the experience of home birth, including the stages of prepartum, childbirth and postpartum and as specific objectives: to draw the sociodemographic profile of the women who gave birth at home; describe care during the stages of home birth; identify factors that influenced the process of home birth; and to verify the participants in the process of home birth. This is a qualitative research with a descriptive approach, carried out in households of a municipality of Recôncavo da Bahia. Ten women who had undergone home birth participated. A semi-structured interview was used and data were analyzed using the content analysis technique. The results showed that women preferred home delivery, and among the factors of influence they mentioned the participation of relatives, the performance of the team, the adoption of nonpharmacological methods and feeding during labor. Among the complications they reported postpartum hemorrhage, perineal laceration and complication for the newborn. It is suggested that a bill be drafted with the

\footnotetext{
${ }^{1}$ Parteiro. Enfermeiro Graduado pela Faculdade Maria Milza - FAMAM. Especialista em enfermagem obstétrica pela FAMAM. Atua na Santa Casa de Misericórdia de Cruz das Almas como enfermeiro obstetra. E-mail: crysnanno@hotmail.com. LATTES: http://lattes.cnpq.br/0020677239533230.

${ }^{2}$ Enfermeira Obstetra, Especialista em Educação Permanente e Saúde e preceptoria do SUS. Mestra em Desenvolvimento Regional e Meio Ambiente; Orientadora da pesquisa; Docente da graduação em Enfermagem da Faculdade Maria Milza - FAMAM e da especialização em enfermagem obstétrica da EBMSP. E-mail: camilatorrespaz@gmail.com. LATTES: http://lattes.cnpq.br/1880862855767805.

${ }^{3}$ Doutora em Geologia Ambiental (UFBA), Mestre na Área de Recursos Naturais e Especialista em Metodologia da Pesquisa. Coord. do Programa de Iniciação Científica da FAMAM; Docente do Programa de Mestrado em Desenvolvimento Regional e Meio Ambiente (FAMAM) andreajsb@gmail.com; LATTES: http://lattes.cnpq.br/5984997883918707.

${ }^{4}$ Graduanda em Enfermagem pela Faculdade Maria Milza - FAMAM. Email: fragabia@hotmail.com. LATTES: http://lattes.cnpq.br/2390902166913382.

${ }^{5}$ Graduada em medicina pela UFBA; Bacharel Interdisciplinar em Saúde/UFBA, juliette.borges@hotmail.com
} 
purpose of regulating and valuing the practice of home birth in Brazil, with the allocation of financial resources for the training of personnel and the acquisition of material resources to guarantee the effectiveness of care.

Key words: Obstetric Nursing. Home Birth. Nursing Assistance.

\section{INTRODUÇÃO}

O parto é considerado um momento inesquecível na vida das mulheres, por se tratar de uma união de acontecimentos fisiológicos, emocionais, assistenciais e sociais que permitem o surgimento de um novo ser. Sendo assim, Martins, Almeida e Matos (2012, p. 313) referem que "o parto é um processo fisiológico na vida da mulher, onde o seu corpo é preparado durante o período gestacional para o nascimento de seu filho".

Existem 5 (cinco) tipos de parto que são: o parto cesáreo, natural (vaginal sem uso de intervenções medicamentosas ou invasivas), normal (com o uso de intervenções medicamentosas ou invasivas), fórceps e domiciliar (CARNEIRO et al., 2015; LEROY; LÚCIO; LOPES, 2016).

No passado, a assistência ao parto era prestada por parteiras, predominantemente no domicílio, com acesso limitado a recursos e representava, em sua essência, um evento familiar. Ao passar dos anos e com o rápido avanço tecnológico e industrial, o parto institucionalizou-se, centrado na figura do médico e passou a ser medicalizado e intervencionista (SANTOS et al., 2018).

Para a transformação do cenário atual, são fundamentais mudanças do modelo de atenção ao parto e nascimento e qualificação da assistência prestada. O Ministério da Saúde (2011), com a iniciativa denominada Rede Cegonha, propõe essa mudança com a proposta de atuação de equipes multiprofissionais, incluindo a enfermagem obstétrica/obstetriz (ÁVILA et al., 2017).

Diante disso, acredita-se que o parto domiciliar pode ser uma proposta de parto humanizado, por permitir que a mulher permaneça em sua residência, próxima a pessoas que fazem parte do seu convívio familiar. Ainda, este tipo de parto proporciona à mulher um ambiente mais confortável (se tratando do seu próprio lar), onde a mesma pode realizar suas atividades diárias, sem necessitar de intervenções e períodos prolongados de jejum e escolher o local e o posicionamento mais adequado para o processo de parição.

Nesse sentido, o estudo buscou responder à seguinte pregunta: qual a concepção de mulheres sobre o parto domiciliar quanto às etapas do pré-parto, parto e pós-parto?

Nesse contexto, a pesquisa teve como objetivo geral conhecer a concepção de mulheres sobre a experiência do parto domiciliar, incluindo as etapas do pré-parto, parto e pós-parto. Em consonância, os objetivos específicos são: traçar o perfil sociodemográfico das mulheres que pariram em domicílio; descrever a assistência durante as etapas do parto; e identificar fatores e intervenientes que influenciaram no processo

Acredita-se que esta pesquisa traz novos olhares para a modalidade de parto domiciliar, mostrando a sua importância por proporcionar à mulher um ambiente mais acolhedor. Poderá também despertar os gestores para elaboração de políticas públicas que regulamentem e garantam o direito ao exercício do parto planejado como um modelo de assistência tão resolutivo quanto o modelo hospitalocêntrico, permitindo assim que as mulheres que possuam gestação de baixo risco tenham o direito de escolher o tipo de parto a ser realizado. Também possibilitará a criação de cursos de capacitação, para que os profissionais que atuam na assistência obstétrica possam interessar-se pelo exercício do parto domiciliar.

\section{PERCURSO METODOLÓGICO}

Esta pesquisa de campo de abordagem qualitativa foi realizada em domicílios localizados no município de Cachoeira, no Recôncavo da Bahia. Esta cidade conta com cerca de 34.000 habitantes e possui uma unidade hospitalar de atendimento pelo SUS, a Santa Casa de Misericórdia do município, 
Hospital São João de Deus. Segundo dados de 2013, esta unidade hospitalar dispunha de 11 leitos para a assistência obstétrica (05 para partos normais e 06 destinados a partos cesáreos) (DATASUS, 2013; IBGE, 2010).

Participaram da pesquisa mulheres que já tinham vivenciado a modalidade do parto domiciliar. Para identificação das mulheres foi utilizada a técnica da bola de neve e saturação dos dados para a definição da amostra final, totalizando dez mulheres participantes. Nesta técnica, o pesquisador especifica as características que os membros da amostra deverão ter, depois identifica uma pessoa ou um grupo de pessoas que se enquadrem dentro dos objetivos do esudo. Em seguida, apresenta a proposta do estudo e, após obter/registrar os dados, solicita que os participantes da pesquisa indiquem outras pessoas pertencentes à mesma população-alvo, até o ponto de saturação, quando não são necessárias mais indicações (COSTA, 2018).

O projeto foi aprovado pelo Comitê de Ética da Faculdade Maria Milza com o número 2.031.570. Os participantes, no momento de assinaram o Termo de Consentimento Livre e Esclarecido (TCLE) foram comunicados de que, para preservar sua identidade, seus nomes seriam trocados pelo de flores.

Para a seleção e inclusão das mulheres foram utilizados os critérios: ser maior de 18 anos, ter parido em ambiente domiciliar, independentemente do número de partos, e que concordaram em participar da pesquisa através da assinatura do TCLE. Quanto aos critérios de exclusão foram: puérperas que pariram em outro ambiente que não seja o domiciliar e que não tivessem sido assistidas por um enfermeiro no momento do parto, porém não houve nenhuma exclusão.

Foi feito um levantamento com o auxílio de agentes comunitários de saúde do município (de maneira informal) para auxiliar na busca ativa da primeira mulher que tinha vivenciado o parto domiciliar a fim de convidá-la para participar da pesquisa. Em seguida, essa mesma mulher indicou a próxima mulher para participar do estudo, e assim sucessivamente.

A entrevista semiestruturada inicialmente contou com um roteiro contemplando oito perguntas; porém, durante o desenvolvimento da mesma foram inseridas mais duas, totalizando dez questões. No roteiro constaram questões referentes ao parto em domicílio, às técnicas humanizadoras do parto, o profissional que acompanhou o período, as possíveis complicações pós-parto, os benefícios ou malefícios do ponto de vista das participantes, gerados pelo parto domiciliar e concepção das mesmas quanto à postura do profissional na assistência ao parto.

Vale destacar que a entrevista foi realizada no próprio domicílio da paciente, sendo registrada através de um gravador e, em seguida, as falas foram transcritas na íntegra e, posteriormente, deu-se andamento à análise dos dados obtidos.

Para analisar os dados foi utilizada a análise de conteúdo de Minayo (2011), a qual se divide em três etapas, a saber: pré-análise, exploração do material e tratamento e interpretação dos dados. Este tipo de análise é comum para a pesquisa de natureza qualitativa. Portanto, a partir da análise interpretativa dos dados foi que emergiram as categorias de discussão.

\section{RESULTADOS E DISCUSSÃO}

\section{CARACTERIZAÇÃO SOCIODEMOGRÁFICADAS PARTICIPANTES DO ESTUDO}

Nesta pesquisa participaram 10 mulheres, com idade entre 25 e 39 anos, todas residentes na zona rural, sendo que a maioria trabalha como lavradora $(n=7)$, as demais são domésticas $(n=2)$ e do lar $(n=1)$. Sanfelice e Shimo (2016) trazem dados semelhantes a esta pesquisa, com um público de 14 mulheres com a mesma faixa etária, que optaram pelo parto domiciliar planejado. As participantes referiram ainda que vivem da agricultura de subsistência e ainda, possuem o auxílio Bolsa Família do Governo Federal, destinado a famílias de baixa renda. Quanto ao estado civil, nove entrevistadas referiram "união estável" (Tabela 1). 
Tabela 1. Distribuição das entrevistadas quanto a idade, profissão e estado civil.

\begin{tabular}{l|c|c|c}
\hline PARTICIPANTES & IDADE & PROFISSÃO & ESTADO CIVIL \\
\hline Flor de Lis & 28 & lavradora & união estável \\
\hline Rosa & 25 & lavradora & união estável \\
\hline Margarida & 39 & lavradora & união estável \\
\hline Bromélia & 42 & lavradora & união estável \\
\hline Begônia & 29 & lavradora & união estável \\
\hline Lírio & 37 & lavradora & união estável \\
\hline Cravo & 33 & lavradora & união estável \\
\hline Girassol & 38 & doméstica & união estável \\
\hline Dália & 39 & doméstica & união estável \\
\hline Orquídea & 33 & do lar & casada \\
\hline
\end{tabular}

Fonte: Dados da pesquisa, 2017.

Percebe-se que apenas as entrevistadas "Girassol" e "Dália" trabalham fora de casa, as demais atuam na própria zona rural, nas atividades de agricultura familiar. Isto pode estar relacionado ao fato de que as mesmas, por residirem na zona rural, culturalmente permanecem atuando junto a seus familiares como lavradoras.

Das participantes, 05 são primíparas (um parto), 03 delas secundíparas (dois partos), 02 multíparas (quatro ou mais partos). De acordo com as informações colhidas, a maioria das participantes $(\mathrm{n}=7)$ teve um ou mais abortos (Tabela 2$)$.

Tabela 2. Percentual das participantes da pesquisa quanto ao número de gestações.

\begin{tabular}{c|c}
\hline NÚMERO DE GESTAÇÕES & FREQUÊNCIA \\
\hline Multigesta & $30 \%$ \\
Primigesta & $30 \%$ \\
Secundigesta & $30 \%$ \\
Tercigesta & $10 \%$ \\
\hline
\end{tabular}

Fonte: dados da pesquisa, 2017.

Diante do exposto, no que tange ao número de gestações, as participantes Bromélia, Girassol e Dália, correspondem à $30 \%$ das mulheres multigestas, e estas apresentam idade maior quando comparadas às demais, conforme evidenciado nas informações comparadas da Tabela 1 e Quadro 1. Isto significa que há uma relação diretamente proporcional entre o número de gestações e a idade das mulheres. No entanto, este dado não é absoluto nos padrões femininos da sociedade atualmente, onde

Quadro 1. Distribuição das entrevistas quanto às modalidades de parto vivenciadas.

\begin{tabular}{|l|c|c|c|}
\hline PARTICIPANTES & $\begin{array}{c}\text { N DE PARTOS } \\
\text { DOMICILIARES }\end{array}$ & $\begin{array}{c}\text { OUTRAS MODALIDADES } \\
\text { DE PARTO }\end{array}$ & ABORTO \\
\hline Flor de Lis & 1 & 1 & 0 \\
\hline Rosa & 2 & 0 & 0 \\
\hline Margarida & 1 & 0 & 1 \\
\hline Bromélia & 2 & 4 & 0 \\
\hline Begônia & 1 & 0 & 0 \\
\hline Lírio & 1 & $1^{*}$ & 0 \\
\hline Cravo & 1 & 0 & 0 \\
\hline Girassol & 6 & 0 & 0 \\
\hline Dália & 1 & 0 & 4 \\
\hline Orquídea & 1 & 0 & 0 \\
\hline
\end{tabular}

*- Gestação gemelar, óbito de um dos recém-nascidos.

Fonte: Dados da pesquisa, 2017. 
as mulheres, principalmente que vivem em zona urbana, tem se inserido no mercado de trabalho e não apenas nas responsabilidades do lar e cuidados dos filhos. Assim, as grandezas tornam-se inversamente proporcionais, visto que, na atual conjuntura da sociedade, a mulher opta por ter menor quantidade de filhos, e numa idade mais avançada.

O Quadro 1 contem o quantitativo de partos em domicílio das mulheres entrevistadas.

Tendo em vista a predominância de partos domiciliares ocorridos nesta pesquisa, considerando que as entrevistadas residem em território rural, consequentemente afastadas das maternidades, acredita-se que esta modalidade de parto está intimamente relacionada a este fator, uma vez que o acesso à assistência hospitalar se torna mais difícil. Brasil (2015) aponta que os índices de partos domiciliares realizados em 2015 não ultrapassaram 1\% dos 3 milhões de nascimentos que ocorreram, evidenciando a prevalência do parto institucionalizado.

Embora não tenha sido especificado nesta pesquisa, existem mulheres que optam pelo parto domiciliar planejado, ou seja, o parto é programado entre a gestante e o profissional devidamente capacitado para a atuação na assistência ao parto normal, como é o caso das parteiras. Apesar disso, o relato das entrevistadas aponta que a maioria delas foi assistida por uma equipe multiprofissional, sendo que as mulheres receberam a visita desta equipe antes do dia do parto. Retratam ainda vivências do parto hospitalar anteriormente como algo negativo comparado ao parto ocorrido em domicílio. Desta forma, pode-se inferir que a maioria das participantes planejou o parto domiciliar.

Sanfelice e Shimo (2014) destacam que a escolha do parto domiciliar planejado tem sido opção para mulheres, mesmo em grandes centros urbanos, devido ao atual modelo de parto hospitalar, no qual tem se evidenciado altos índices de violência obstétrica.

Vasquez, Schidmit e Sehnem (2016) complementam ainda que o aumento indiscriminado de intervenções médicas e o alto índice de partos cesáreos têm transformado o perfil mundial de assistência obstétrica e causado elevado número de mortes maternas e perinatais.

Embora o parto domiciliar seja mais frequente em lugares de difícil acesso aos centros urbanos, Moraes et al. (2016) afirmam em seu estudo que o parto domiciliar planejado tem sido uma alternativa para casais que desejam vivenciar o momento do parto de forma mais satisfatória, considerando que a mulher e seus familiares têm a liberdade de acompanhar todo o processo e contribuir de maneira positiva, diminuindo os medos e anseios da mulher.

\section{ASSISTÊNCIADURANTEASETAPAS DO PARTO DOMICILIAR}

O cuidado profissional prestado à mulher em trabalho de parto é de extrema importância para a mesma. Sanfelice e Shimo (2016) afirmam que o posicionamento da equipe de saúde que a assiste em domicilio propicia à parturiente uma participação ativa no processo de parir.

Collaço et al. (2016) acrescentam que a partir do momento em que a mulher é vista como protagonista do seu parto, a equipe atua fazendo as recomendações necessárias, explicando os riscos e benefícios, de forma que a mulher tenha autonomia para decidir como deseja proceder. Logo, é necessário que os profissionais que lidam com a assistência obstétrica estejam aptos a prestar à mulher todas as informações relevantes no momento do parto. Neste contexto, Silva et al. (2016) ressaltam que a humanização na assistência ao parto envolve diretamente o protagonismo e autonomia da mulher, sendo estes relacionados ao compartilhamento e apropriação de direitos e saberes.

Com relação à composição da equipe multiprofissional que acompanhou o parto das entrevistadas, Orquídea, Dália, Cravo e Girassol relataram que foram assistidas por equipes com a mesma composição profissional, conforme destacado nas falas das mesmas, a seguir:

Uma enfermeira, uma doula, um enfermeiro e uma fisioterapeuta (Orquídea).

Os quatro primeiros "foi" com uma parteira, os dois últimos "foi" com uma enfermeira, um enfermeiro, e uma fisioterapeuta (Girassol).

As percas era eu sozinha, depois a parteira vinha ver como eu estava e me ensinava chá 
e eu ficava boa, desse último foi uma enfermeira, um enfermeiro, uma doula e uma fisioterapeuta (Dália).

Uma enfermeira, um enfermeiro, uma doula, e uma estudante de fisioterapia (Cravo).

A partir do exposto pelas mulheres, destacam-se os relatos de Girassol e Dália, que citam a presença da parteira nos processos parturitivos, visto que, atualmente, tal participação não acontece de maneira rotineira.

No passado, os partos eram acompanhados, prioritariamente, em ambiente domiciliar, por parteiras ou mulheres de afinidade e confiança da gestante. A assistência à parturiente era considerada um assunto feminino, envolvendo laços emocionais, crenças, talismãs e orações, um assunto de mulheres (VARGENS; SILVA; PROGIANTI, 2017)

A participação de parteiras também está presente no histórico de partos das entrevistadas "Bromélia" e "Rosa". Além disso, tem-se a presença das doulas, que são mulheres que não precisam, obrigatoriamente, serem profissionais da área, e que atuam voluntariamente com o propósito de oferecer à parturiente suporte emocional, espiritual, social e físico, sendo esta participação reconhecida de maneira positiva pelas mulheres em trabalho de parto, como também pelos profissionais de saúde (SILVA et al., 2012). A atuação da doula é destacada por "Margarida" na fala abaixo:

Nunca tinha ouvido falar que tinha essa pessoa, mas ela me tratou tão bem, me deu muita força (Margarida).

Verifica-se que a presença da enfermeira obstetra no parto domiciliar, apesar de ser um direito da gestante amparado pelo Ministério da Saúde (MS), não sempre é exigida por muitas gestantes, devido ao desconhecimento dos seus próprios direitos. Para mudar essa realidades é necessário divulgar informações da Rede Cegonha, com vistas a fornecer às gestantes todos os direitos previstos na lei.

Quanto à presença da enfermeira obstetra no parto domiciliar, Sanfelice et al. (2014) destacam que, mundialmente, esta profissional já é reconhecida como a mais adequada para prestar os cuidados à parturiente, e a mais econômica. Lírio comenta a respeito da atenção do profissional enfermeiro durante o seu parto em domicílio na fala em destaque:

Sinceramente eu gostei mais que se fosse só com uma parteira, não que eu desmereça o trabalho dela, mas os enfermeiros são mais treinados, todos ali o tempo todo olhando minha pressão. Me escutando, ouvindo o coração do bebê, foi incrível!!! (Lírio).

De acordo com Silva (2015), o movimento objetivando a humanização do parto tem dado maior visibilidade para a atuação dos profissionais de enfermagem no processo parturitivo, tornando a atuação destes cada vez mais respeitada neste âmbito. Logo, é notório o reconhecimento da entrevistada quanto aos cuidados do(a) enfermeiro(a) na assistência obstétrica, devido ao apoio emocional, bem como às habilidades técnico-científicas apresentadas por estes profissionais durante a assistência.

Ainda no âmbito da assistência prestada, o cuidado holístico não se restringe apenas ao parto, deve envolver cuidados também no pós-parto, como ilustram as falas abaixo:

Justiça se faça a equipe foi nota dez, ficaram comigo o tempo todo. Até depois que pari, eles ainda ficaram até de noite lá, cuidaram de meu bebê e me ensinaram a dar de mamar que eu já tinha esquecido; ficou acompanhando por quase um mês (Flor de Lis).

Como já conheço a parteira foi tranquilo, e a enfermeira me deu muita atenção [...] fui muito bem atendida. Quase todos os dias ela ia me ver ou ligava pra saber de mim [...] (Rosa).

Todos foram muito cuidadosos comigo. A enfermeira toda hora olhava minha pressão, $e$ 
depois que pari ela ficou até de manhã lá, e até no dia que fui vacinar ela me acompanhou (Margarida).

Nossa! A equipe foi perfeita! [...] Fui muito bem tratada até depois que pari, elas me acompanharam por um tempo (Begônia).

Foi sensacional a forma como fui tratada, parecia que era até particular [...] eles me acompanharam o resto da noite e no dia que fui pro PSF eles foram junto, achei isso lindo (Cravo).

Diante desses depoimentos, percebe-se que a equipe foi lembrada de maneira positiva pelas participantes desta pesquisa, destacando-se os adjetivos "nota dez", "cuidadosos", "perfeita" e "sensacional" apresentados pelas mesmas. Outro ponto notável nos comentários foi o acompanhamento feito pelos profissionais a estas mulheres mesmo após o nascimento do bebê, muito embora esta seja uma atribuição a ser desenvolvida pela enfermeira das Unidades de Saúde da Família.

Percebe-se que entre os profissionais que assistiram ao parto em domicílio não há referência à presença do médico. Nesse sentido, Mattos, Vandenberghe e Martins (2016) destacam que esta categoria profissional geralmente está distante da realidade dos partos domiciliares planejados, embora muitos apreciem esta modalidade, na qual o enfermeiro assume o papel principal.

A entrevistada Dália, após ter tido abortos espontâneos subsequentes, refere em sua fala o posicionamento do médico durante a consulta de acompanhamento, quando ela manifestou o desejo de parir em casa:

Eu fiz todo pré-natal que eles mandaram fazer, passei no doutor também, fiz ultrassom, e o pessoal examinou tudo, o medico sabia que eu queria ter em casa, me meteu medo e disse que já que eu queria, ele não podia fazer nada, mas que não estava vendo nenhum risco não, mas que era melhor eu ter na maternidade (Dália).

Nota-se que, no relato da participante, o profissional que a acompanhou, embora não tenha concordado totalmente com a escolha da mesma, não a proibiu de parir em casa, afirmando que não havia um risco iminente que a impediria de realizar o seu desejo.

Quando questionadas quanto ao tempo em que haviam vivenciado o parto em domicílio, a maioria das mulheres $(n=09)$ referiu ter parido há 04 anos ou abaixo desse período. Sanfelice e Shimo (2016) afirmam que o parir no ambiente doméstico permite uma nova concepção do parto e nascimento, onde dificilmente ocorrem situações de violência obstétrica (deboche e proibição da livre expressão da mulher), comumente registradas em instituições hospitalares.

Outro fator importante é o apoio do acompanhante (marido/companheiro ou familiar), que é configurado como um suporte contínuo durante o trabalho de parto, o que favorece uma vivência positiva do processo de parturição (SILVA et al., 2017). Neste caso, a presença de um acompanhante de escolha da mulher durante o trabalho de parto é regulamentada através da Lei do Acompanhante de $n^{\circ} 11.108 \mathrm{e}$ reforçada por Sanfelice e Shimo (2016) em sua pesquisa, na qual demonstra a importância deste no processo parturitivo das mulheres, fornecendo segurança e bem-estar. Neste sentido, as entrevistadas relataram a presença dos familiares durante a assistência ao parto domiciliar, conforme descrevem Flor de Lis, Begônia e Margarida.

Eu pude estar com toda minha familia em volta naquela hora, e o meu outro filho estava assistindo tudo, depois minha mãe fez uma comida maravilhosa pra mim (Flor de Lis).

Só em ter minha família ali comigo foi tudo, e depois deu pra tomar banho e comer a vontade (Margarida).

A melhor parte foi meu marido do lado, ele mesmo que cortou o cordão umbilical 
(Begônia).

Percebe-se que a presença da família no trabalho de parto pode trazer resultados positivos para a parturiente, como fica evidente nos depoimentos das participantes, quando recuperam lembranças significativas de apoio e suporte emocional, como se depreende do relato de Begônia, cujo marido cortou o cordão umbilical, reforçando os laços afetivos entre pai e filho.

Além da presença dos familiares, existem outros fatores que são determinantes no parto em domicílio e que detalharemos na próxima seção.

\section{FATORES QUE INFLUENCIARAM NO PROCESSO DO PARTO DOMICILIAR}

O processo de parir em casa acompanhada por pessoas íntimas e profissionais comprometidos com a assistência proporcionam à mulher um ambiente calmo, seguro e de bem-estar (SANFELICE; SHIMO, 2016). Além disso, Nascimento et al., (2016) destacam que o ambiente hospitalar é visto, na maioria das vezes, como um local que traz medo e insegurança, além de adotar práticas desmotivadoras e ruins do ponto de vista das parturientes. Este fato também foi evidenciado na pesquisa, quando as mulheres comparam o parto hospitalar com o domiciliar:

Não gostei, pois não tive direito nem de gritar (Flor de Lis).

Ter meus filhos do lado e meu marido, e também não ter que ficar no hospital sem necessidade, depois eu pude comer à vontade tudo que queria (Girassol).

Ficar com meus filhos do lado foi o melhor, e minha mãe viu meu filho nascer antes dela falecer, pois era o sonho dela. Se fosse na maternidade isso não acontecia (Bromélia).

Foi bom por que foi tudo como eu queria! Só minha família junto, sem cortar do lado da minha vagina, sem luz na minha cara e ainda eles cantando me ajudou muito (Lírio).

$\mathrm{Na}$ comparação entre o parto hospitalar e o domiciliar percebe-se uma clara preferência das entrevistadas pelo segundo. Assim, por exemplo, Flor de Lis afirma que durante o parto hospitalar foi impedida de expressar-se nos momentos de dor. Rosa e Girassol, por sua vez, destacam o alívio por não precisar ficar internada. Já Bromélia ressalta a participação da mãe durante o seu parto domiciliar, o que segundo a entrevistada não poderia ocorrer na maternidade. Além disso, Lírio retrata a experiência vivida no hospital lembrando da episiotomia e dos focos de luz. A episiotomia, atualmente é uma prática desestimulada pelo MS, através da Portaria 1.459/2011 que regulamenta a Rede Cegonha, considerando esta e outras medidas invasivas como desnecessárias, muito embora ela seja ainda adotada, e de maneira abusiva, nas unidades hospitalares (SOUSA, 2016).

Nas suas falas as mulheres lembram a experiência do parto hospitalar como algo negativo, que não traz sensação de prazer e boas recordações. Isso pode se dever a que o ambiente hospitalar remete muito mais a doenças do que à vida, sendo, portanto, necessário oferecer à mulher mais apoio psicoemocional para ajudá-la a superar seus medos, anseios e dores provocados pelo parto.

Diante dos relatos, é possível concluir que o parto domiciliar possui pontos positivos que o tornam mais agradável do que o parto hospitalar, desde que não haja riscos ao binômio mãe-filho durante o trabalho de parto e parto. Neste contexto, Silva (2015) analisa em seu estudo os benefícios relacionados ao parto em domicílio, destacando como mais importantes o apoio familiar, o protagonismo da mulher, a confiança nos profissionais, o apoio psicoemocional, o ambiente acolhedor, sem uso de medidas invasivas ou medicamentosas e respeito à evolução fisiológica do parto.

Outro ponto importante foi a atuação da equipe multiprofissional que acompanhou o parto e puerpério imediato, que evoca lembranças afetivas dos cuidados prestados, entre eles os MNFs como massagens, técnicas de relaxamento, agachamento e banho, bem como o apoio psicoemocional.

Para Viana, Ferreira e Mesquita (2013), os MNFs são medidas utilizadas visando proporcionar o 
alívio da dor, além de dar conforto e promover o bem-estar da parturiente, respeitando seus limites e suas necessidades. Nesse sentido, cabe destacar algumas das falas das entrevistadas:

Elas me orientavam a respirar devagar, fizeram massagens, tomei vários banhos, e me deram mel pra eu ficar forte. Ah! e me mandaram caminhar bastante (Flor de Lis).

Fizeram bastante massagem! Até na vagina fez massagem! Tomei banho o tempo todo, $e$ chá, caminhare agachar (Margarida).

Elas me mandaram andar, tomar banho e fizeram massagem... Usaram um óleo cheiroso na massagem! Ficaram cantando o tempo todo louvores! (Bromélia).

Mandaram caminhar bastante! Tomei vários banhos morno. Quando a dor apertou fizeram massagem! Fiquei fraca, me deram mel e chás doces! E agachamento (Begônia).

Todos tinham uma função: os enfermeiros ficaram me ensinando a respirar e vendo minha pressão e ouvindo o bebê; a fisioterapeuta fazia massagens e me ensinou a agachar; a doula também fazia um pouco de massagem e me acompanhava no banho e nas caminhadas (Cravo).

Me ensinaram a respirar certo na hora da dor, me ensinaram a agachar, mandaram tomar banho morno. Até meu marido participou comigo! [...] (Girassol).

Eles me mandavam tomar banhos, caminhar, fizeram massagens, agachamento, e na hora de parir me ensinaram a fazer a força certa que eu só queria fazer na garganta e isso atrapalhou um pouco do menino sair (Dália).

Os textos mostram que as medidas utilizadas pela equipe, como por exemplo as massagens, os banhos, as técnicas de respiração, o agachamento, a deambulação (caminhada) e a alimentação tornaram o processo do trabalho de parto mais confortável, uma vez que promovem o alívio da dor.

Desta forma, compreende-se que as medidas adotadas pela equipe multiprofissional na assistência ao parto domiciliar neste estudo estão respaldadas cientificamente pela publicação das Diretrizes Nacionais da Assistência ao Parto Normal, pelo MS, e comprovadamente proporcionam à mulher em trabalho de parto melhores condições para o enfrentamento da dor.

Além dos MNF, também observa-se nos relatos de três entrevistadas (Begônia, Flor de Lis e Margarida) a presença da ingesta de líquidos (chás e mel) como uma medida positiva que auxiliou durante o processo do parto, prática incentivada pela nova proposta de humanização do parto, através da Rede Cegonha. Outro aspecto relatado pela participante Bromélia foi o uso de musicoterapia, considerada uma MNF que, embora não traga alívio da dor, promove relaxamento e alívio da tensão.

O Quadro 2 mostra que os discursos de todas as entrevistadas foram positivos com relação à vivência do parto em casa.

Quadro 2. Relação de fatores que contribuíram com o processo do parto domiciliar

\begin{tabular}{|l|c|}
\hline FATORES CONTRIBUINTES PARA O PARTO DOMICILIAR & FREQUÊNCIA \\
\hline Presença de familiares & 09 \\
\hline Métodos Não Farmacológicos & 10 \\
\hline Atuação da Equipe Multiprofissional & 10 \\
\hline Alimentação & 05 \\
\hline Ambiente Domiciliar & 06 \\
\hline
\end{tabular}

Fonte: Dados da Pesquisa, 2017. 
Verificou-se que diversos fatores evocam as mesmas lembranças positivas para as mulheres, como o reconhecimento da equipe profissional e o desejo de poder vivenciar esta modalidade de parto novamente (Bromélia e Margarida).

Com relação aos fatores considerados negativos, as entrevistadas falaram do medo de que algo desse errado, porém as mesmas também citam o amparo da equipe, fazendo com que este sentimento se tornasse passageiro, como se depreende das falas abaixo:

No inicio tive medo de ter algum problema com o bebê, mas a todo o momento a equipe me encorajava, só foi isso de negativo mas passou logo (Flor de Lis).

[...] o medo de alguma coisa dar errado, mesmo sendo eu que escolhi ter em casa (Margarida).

Medo de dar errado, mas elas me deram tanta força que passou. Até me sugeriram ir para o hospital, mas não recuei. Fui guerreira !!! Como eles me chamavam (Begônia).

Ainda que eu soubesse de todos os riscos, ainda fica um pouco de medo de acontecer alguma coisa e dar errado, mas eles perceberam e deram muita força. Isso fez o medo passar(Dália).

Segundo Nascimento et al. (2016), este sentimento de medo foi evidenciado também nos relatos de mulheres que pariram no hospital, devido às experiências desagradáveis vivenciadas no local, sendo inclusive uma das justificativas pela escolha do parto domiciliar. Nota-se que tal como na pesquisa destes autores, a entrevistada "Margarida" também relatou que o parto domiciliar foi planejado, o que indica que este modelo de parto estimula a autonomia da mulher, promovendo segurança e confiança à mesma.

Outros pontos negativos foram citados, como o da participante Rosa que, por ter sido de sua escolha permanecer deitada durante o trabalho de parto, acabou achando a cama um pouco desconfortável. Já Bromélia ficou incomodada com a movimentação de pessoas no local, o que aponta para a relevância de que seja respeitada a privacidade da mulher durante o trabalho de parto, assegurando os direitos éticos e morais, permitindo apenas pessoas que sejam do desejo da mesma, cabendo à equipe no momento atentar-se para este detalhe. É importante ressaltar que, pela informação dada pela entrevistada, não é possível determinar se ela estava se referindo a familiares ou à equipe de profissionais de saúde.

\section{COMPLICAÇÕES VIVENCIADAS NO PARTO DOMICILIAR}

Em geral, no parto domiciliar, o profissional de saúde não faz intervenções desnecessárias com o objetivo de acelerar o processo natural de parir, tornando a mulher agente ativa do seu momento (NASCIMENTO et al., 2016).

Entre estas intervenções, tem-se a episiotomia, incisão realizada na região perineal, com a finalidade de facilitar a expulsão do feto no processo de parir. Com relação a essa questão, Margarida e Lírio afirmaram que houve laceração do períneo no parto, que é um processo que ocorre de maneira fisiológica, sem que haja utilização de instrumentos cortantes para agilizar a saída do bebê. Esta informação é fornecida nas falas a seguir:

Só feriu um pouco a vagina embaixo, mas a enfermeira disse que nem precisava ponto, $e$ doeu bastante no lugar, mas fiz os banhos de assento que ela mandou e ficou bom [...] $O$ lugar que ficou doendo muito com esse ferimento, mas passou (Margarida).

Ainda, as entrevistadas Bromélia e Cravo relataram ter apresentado tonturas, sendo que esta última, quando questionada se no momento a mesma desejou ir para o hospital, foi relatado que o cuidado da equipe a fez sentir-se segura para continuar: 
Só quase tive um desmaio devido a ter pressão baixa, mas eles cuidaram logo em me dar logo um leite bem morno e mandaram respirar e voltei ao normal [...] De ruim mesmo só essa tontura depois que saiu a placenta, achei que fosse morrer [...] estava tão amparada por eles, que sabia que ia ficar bem (Cravo).

Também, fiquei tonta, mas se resolveu lá mesmo. [...] (Bromélia).

Outra complicação evidenciada nesta pesquisa foi o sangramento ou hemorragias, conforme destacado nas falas de Bromélia e Girassol. Foi necessário que a equipe administrasse um medicamento injetável prescrito pelo médico, que contivesse o sangramento.

Só sangrou muito, me deram injeção e parou logo, mas senti muita cólica depois, tive que tomar um remédio. (Bromélia).

Fiquei sangrando um pouco, mas eles falaram com um médico e me deram uma injeção, [...] também [...] fez uma massagem no meu útero que parou na hora o sangramento (Girassol).

Ainda, Dália referiu que houve complicações com o bebê, por ela não ter seguido corretamente as orientações da equipe com relação ao processo de parir. Segundo a mesma, o bebê recebeu cuidados que logo normalizaram a situação:

Só mesmo o menino que nasceu um pouco molinho, por que eu não estava fazendo a força certa [...], mas eles fizeram massagem no meu bebê e enxugou ele até que ele foi voltando a ficar rosinha e pronto começou a chorar. (Dália).

Desta maneira, percebe-se a importância de seguir as recomendações da equipe durante a assistência, com o objetivo de não causar problemas ao recém-nascido ou mesmo à mulher. Por outro lado, houve participantes que afirmaram não ter vivenciado nenhum tipo de complicação, conforme as falas abaixo:

Não houve nenhuma complicação! Foi uma benção! (Flor de Lis).

Não tive nada, só depois que senti dor na vagina por alguns dias, mas elas me avisaram que seria normal (Begônia).

Não teve nada de ruim, esse sangramento eu teria em qualquer lugar. Pra mim foi perfeito! (Girassol).

No primeiro eu sangrei muito, mas depois parou. Já no segundo, como falei desse sangramento que tive, elas conversaram com um médico por telefone e ele mandou deixar uma injeção preparada, mas nem precisou. (Rosa)

Embora a participante Girassol tenha apresentado sangramento aumentado logo após o parto, a mesma não considerou este sinal como uma complicação do parto domiciliar, afirmando que poderia ter ocorrido também no ambiente hospitalar.

Com relação ao depoimento de "Rosa", esta faz declaração com relação ao seu primeiro filho, por ter apresentado aumento das loquiações. Porém neste último parto a mesma afirma que a equipe chegou a preparar medicamentos para conter hemorragias, contudo, não houve necessidade de sua utilização. 


\section{CONSIDERAÇÕES FINAIS}

A partir desta pesquisa, foi possível perceber que as entrevistadas, que já vivenciaram as duas modalidades de parto, preferiram o parto domiciliar ao hospitalar. Os resultados mostram que os profissionais que prestaram a assistência ao parto em domicílio foram o (a) enfermeiro (a), bem como a parteira e a doula. Entretanto, não foi evidenciada em nenhum dos relatos a presença do médico na assistência domiciliar direta.

Entre os fatores que influenciaram no processo do parto domiciliar, as participantes destacaram a presença dos familiares e a atuação da equipe multiprofissional. Além disso, a adoção de MNF e alimentação também emergem como pontos positivos neste modelo de parto. Por outro lado, houve pontos negativos, como os sentimentos de medo e insegurança de haver complicações e a circulação de pessoas, mencionada por uma das entrevistadas.

Com relação às complicações apresentadas, as hemorragias pós-parto foram conduzidas com resolutividade e sem sinais de gravidade aparente, além de ser relatado que um dos recém-nascidos apresentou dificuldades ao nascer devido à falta de habilidades da parturiente no ato expulsivo.

Percebe-se que a atuação do enfermeiro é de alta relevância na assistência ao parto domiciliar, não apenas pela técnica de acompanhamento da mulher e do bebê, mas também pelas medidas de apoio psicoemocional.

É notória a importância do reconhecimento do parto domiciliar pelo sistema de saúde do Brasil, pois atualmente este tipo de assistência obstétrica não tem sido valorizado pelas entidades governamentais. É necessário que o poder público invista em recursos materiais e humanos voltados para atender às mulheres que desejam parir em domicílio.

Sugere-se, portanto, que os Conselhos de Enfermagem regionais e federais apresentem projetos de lei com vistas à regulamentação e destinação de recursos para a prática do parto domiciliar. Além disso, por não ter sido especificado nesta pesquisa se a adesão do parto domiciliar foi planejada ou não, sugere-se também a realização de novas pesquisas voltadas para a prevalência de partos domiciliares no Brasil, tendo em vista que as últimas pesquisas evidenciaram o crescimento deste tipo de parto planejado no país, não apenas nos locais mais afastados da assistência hospitalar, como é o caso da zona rural, como também nos grandes centros urbanos.

\section{REFERÊNCIAS}

ÁVILA, A. S. Parto domiciliar planejado: a voz das mulheres sobre sua experiência. Revista Eletrônica Acervo Saúde, Porto Alegre, v. 9, n. 3, p.1251-1257, jun. 2017.

BRASIL. Ministério da Saúde/ Departamento de Informática do SUS - DATASUS. Sistema de Informações sobre Nascidos Vivos (SINASC) 2015.

CARNEIRO, L. M. de A. et al. Parto natural x parto cirúrgico: Percepção de mulheres que vivenciaram os dois momentos. R. Enferm. Cent. O. Min., [s.I.], v. 5, n. 2, p.1574-1585, ago. 2015. Disponível em: <http://www.seer.ufsj.edu.br/index.php/recom/article/view/744/859>. Acesso em: 17 nov. 2018.

COLLAÇO, F. et al. How decentralize denergy planning can contribute to cleaner production initiatives. In: BIAGIO, F. G. et al. Advances In Cleaner Production. Editora: Nova Publisher, 2016.

COSTA, B. R. L. Bola de Neve Virtual: O Uso das Redes Sociais Virtuais no Processo de Coleta de Dados de uma Pesquisa Científica. Revista Interdisciplinar de Gestão Social, Salvador, v. 7, n. 1, p.15-37, jan. 2018.

DATASUS. Tabnet: Nascidos Vivos, Bahia. 2013. 
GERHARDT, T. E; SILVEIRA, D. T. (Org.). Métodos de Pesquisa. Porto Alegre- RS, UFRGS, 2009.

IBGE. Censo demográfico da cidade de Cachoeira - Bahia. Serviços de Saúde. 2010.

KOETTKER, J. G., et al. Resultado de partos domiciliares atendidos por enfermeiras de 2005 a 2009 em Florianópolis, SC. Rev. Saúde Pública, v. 46, n.4, p. 747-750, ago. 2012.

LEROY, L. da S.; LÚCIO, A.; LOPES, M. H. B. de M. Risk factors for postpartum urinary incontinence. Revista da Escola de Enfermagem da Usp, [s.I.], v. 50, n. 2, p.200-207, abr. 2016.

MARTINS, C. A; ALMEIDA, N. A. M; MATTOS, D. V. de. Parto domiciliar planejado: assistido por Enfermeiro Obstétra. Enfermería Global, Murcia, Espanha, v. 1, n. 27, p.312-317, jul. 2012.

MATTOS, D. V. de; VANDENBERGHE, L.; MARTINS, C. A. Motivação de enfermeiros obstetras para o parto domiciliar planejado. REUOL, Recife, v. 8, n. 4, p.951-959, abr. 2014.

MINAYO, M. C. de S. (Org.). Pesquisa social: teoria, método e criatividade. 22. Ed. Rio de Janeiro: Vozes, 2011.

MORAES, P. Á. et al. A dor do parto: percepção de mulheres que pariram no domicílio. Rev. enferm. UFPE online. 2016.

SANFELICE, C. F. O.; SHIMO, A. K. K. Representações sociais sobre o parto domiciliar. Esc Anna Nery, Campinas, v. 19, n. 4, p.606-613, nov. 2015.

SANTOS, S. S. et al. Resultados de partos domiciliares planejados assistidos por enfermeiras obstétricas. Reufsm, Santa Maria, v. 8, n. 1, p.129-143, jan. 2018.

SILVA, C. C. L. Benefícios do parto domiciliar: revisão integrativa da literatura. 2015. 23 f. TCC (Graduação) Curso de Enfermagem, Faculdade de Ceilândia, Ceilândia, 2015.

SILVA, I. A. et al. Percepção das puérperas acerca da assistência de enfermagem no parto humanizado. Uningá, Teresina, p.37-43, jul. 2017.

SILVA, R. M. et al. Evidências qualitativas sobre o acompanhamento por doulas no trabalho de parto e no parto. Ciência \& Saúde Coletiva, Fortaleza, v. 17, n. 10, p.2783-2794, abr. 2012.

SOUSA, A. M. M. Práticas obstétricas na assistência ao parto e nascimento em uma maternidade de belo horizonte. 2013. 139 f. Dissertação (Mestrado) - Curso de Enfermagem, Universidade Federal de Minas Gerais, Belo Horizonte, 2013. Disponível em: <http://www.bibliotecadigital.ufmg.br/dspace/handle/1843/GCPA-97BHGB>. Acesso em: 28 mar. 2016.

VARGENS, O. M. C.; SILVA, A. C. V. da; PROGIANTI, J. M. Contribuição de enfermeiras obstétricas para consolidação do parto humanizado em maternidades no Rio de Janeiro-Brasil. Esc Anna Nery, Rio de Janeiro, v. 21, n. 1, p.1-8, jan. 2017.

VASQUEZ, M. E. D.; SEHNEM, G. D.; SCHMIDT, A. Parto domiciliar: uma revisão integrativa acerca das produções científicas da enfermagem obstétrica. Salão Internacional de Ensino, Pesquisa e Extensão, Uruguaiana, v. 8, n. 2, p.1-3, jun. 2016.

VIANA, L. V. M.; FERREIRA, K. M.; MESQUITA, M. A. S. B. Humanização do parto normal: uma revisão de literatura. Rev. Saúde em Foco, Teresina, v. 1, n. 2, p.134-148, ago./dez. 2014. 